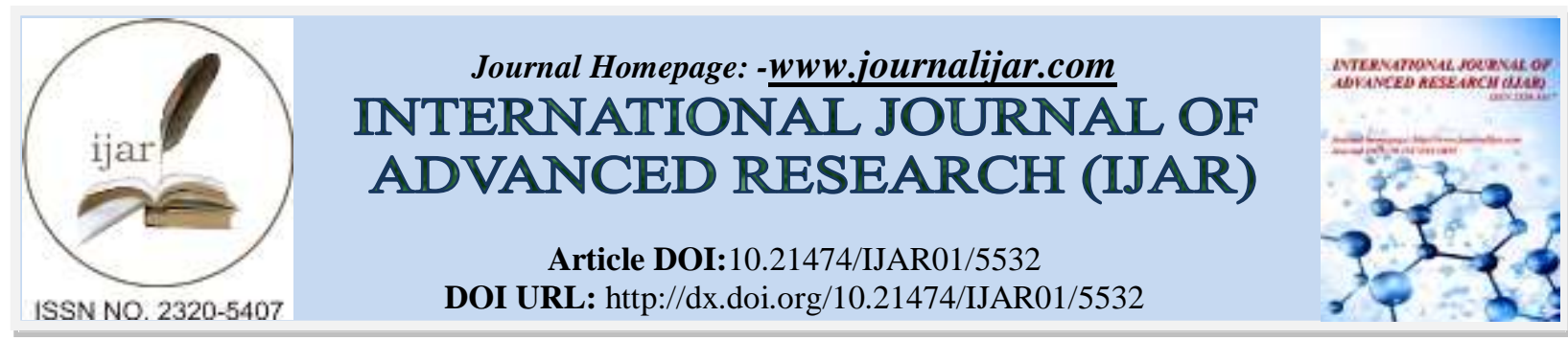

RESEARCH ARTICLE

\title{
A COMPARATIVE STUDY BETWEEN PREOPERATIVE USE OF MISOPROSTOL AND DINOPROSTONE FOR REDUCTION OF HEMORRHAGE DURING ABDOMINAL MYOMECTOMY.
}

\author{
El-Sayed A. El-Naggar, MD, Youssef A. El-Sayed, MD, Walid A. Mohamed, MD, Essa M. Arfa, MD and \\ Engy M. El-Sagheer.
}

\section{Manuscript Info}

Manuscript History

Received: 04 August 2017

Final Accepted: 06 September 2017

Published: October 2017

\section{Abstract}

Aim of work: is to compare the effect of a single preoperative dose of vaginal prostaglandin E1 (misoprostol $400 \mathrm{ug}$ ) versus vaginal Prostaglandin $\mathrm{E}_{2}\left(\mathrm{PGE}_{2}\right.$; dinoprostone 20mg) suppository on reducing intraoperative blood loss and the need for subsequent blood transfusion during abdominal myomectomy for symptomatic leiomyomas.

Patients and methods: The study included 93 women undergoing abdominal myomectomy for symptomatic uterine myoma after complete counseling, and the patients were randomized by random method into three groups.

Result: There was statistical high significant difference between preoperative and postoperative hemoglobin changes in group A, group $\mathrm{B}$ and group C. There was statistical high significant difference between preoperative and postoperative Hct changes in group A, group $\mathrm{B}$ and group C.

Conclusion:The use of vaginal misoprostol or dinoprostone is an effective method to reduce intraoperative hemorrhage during abdominal myomectomy. Also, a single, preoperative dose of dinoprostone administered intravaginally could be safe and reliable method to help decrease blood loss during abdominal myomectomy.

Copy Right, IJAR, 2017,. All rights reserved.

\section{Introduction:-}

Myomectomy is the surgical removal of the myomas with reconstruction and preservation of the uterus. However Excessive hemorrhage during abdominal myomectomy remains a challenge to gynecologic surgeons ${ }^{(1)}$.

Three categories of interventions to reduce bleeding during myomectomy can be identified: intervention on uterine arteries such as laparoscopic uterine artery dissection, uterine artery embolization, pericervical mechanical tourniquet and hormonal tourniquets such as vasopressin and terlipressin; uterotonics such as ergometrine, oxytocin, misoprostol, and sulprostone; and myoma dissection techniques which include the use of laser and chemical dissectors such sa sodium-2-mercaptoethanesulfonate (mesna) ${ }^{(2)}$.

Prostaglandins are known to increase myometrial contractions and lead to a reduction in intra operative bleeding and therefore decrease the requirement of blood transfusion. Misoprostol is a drug that is used for the prevention of Non-steroidal Anti-Inflammatory Drug (NSAID)-inducedgastric ulcers and induction of abortion and early miscarriage .Misoprostol (a synthetic prostaglandin E1 analog)isawater-soluble, viscous liquid. Inactive ingredients of tablets are hydrogenate castor oil, hypromellose, microcrystalline cellulose, and sodium starch glycolate ${ }^{(2,3,4,5)}$. 
Dinoprostone, a prostaglandin $\mathrm{E}_{2}$ analog, has been widely used in clinical practice in obstetrics to control postpartum hemorrhage. It stimulates uterine contractions, and this leads to contraction of the vessels supplying blood to the leiomyomas. This subsequently may redistribute the blood from the diseased uterus back to the circulation, hence reducing operative blood loss during abdominal myomectomy ${ }^{(6,7,8)}$.

The aim of this work is to compare the effect of a single preoperative dose of vaginal prostaglandin E1(misoprostol $400 \mathrm{ug}$ ) versus vaginal Prostaglandin $\mathrm{E}_{2}\left(\mathrm{PGE}_{2}\right.$; dinoprostone 20mg) suppository on reducing intraoperative blood loss and the need for subsequent blood transfusion during abdominal myomectomy for symptomatic leiomyomas .

\section{Patients and methods:-}

This randomized placebo-controlled study was approved by the ethical committee of Zagazig University Hospital, faculty of medicine. The study was conducted atObstetrics and Gynecology Department, Zagazig University Hospitals; the patients were recruited from the gynecological outpatient clinic of the hospital.

The study included 93 women (with symptomatic uterine leiomyoma of maximum anteroposterior diameter $90 \mathrm{~mm}$ and maximum transverse diameter $90 \mathrm{~mm}$ ) undergoing abdominal myomectomy for symptomatic uterine myoma after complete counseling. Sample size was calculated to give a statistical power of $80 \%$ at a $95 \%$ confidence interval.

The following patients were not included in the study: patients having hypertension, cardiac and pulmonary disease, chronic endocrine or metabolic diseases such as diabetes; ppatients known to be allergic to misoprostol; patients having a history of previous surgery; patients receiving preoperative hormonal therapy that can affect intra operative bleeding as (GnRH analogue or oral contraceptive pills) and patients with mental impairment or incompetent in giving consent.

The patients were randomized by random method into three groups:

Group (A) included 31 patients receiving a single preoperative dose of vaginal misoprostol (misotec400ug, sigma) about 2 hours before the operation.

Group (B) included 31 patients receiving a single preoperative dose of vaginal dinoprostone (dinoglandin20mg, egypharm) about 2 hours before the operation.

Group (C) included 31 patients receiving a single preoperative dose of placebo (glycerin, pharco) vaginal suppository about 2 hours before the operation.

All patients were subjected to history taking, general examination, abdominal examination, bimanual and vaginal examinations, routine laboratory investigations including complete blood count, urine analysis, coagulation profile, fasting and postprandial glucose level and liver and kidney function tests and ultrasound study to identify the number and localization of myomas and the largest myoma diameter.

All patients were informed about the study and signed informed consent. Blood samples were taken for hemoglobin assessment 24 hours before the operation.

Two hours before the operation, 31 of the patients will receive misoprostol (misotec400ug,sigma)vaginal suppository, 31of the patients will receive dinoprostone (dinoglandin20mg, egypharm) vaginal suppository,31of the patients will receive placebo (glycerin, pharco) vaginal suppository.

Myomectomy was carried out by two gynecologists. A longitudinal, unipolar incision, possibly close to the midline, or scissors incision, was performed in the uterus. After the identification of the cleavage plane, leiomyoma was enucleated by means of adequate traction with a myoma drill or a strong grasper and counter traction , the nearby myomas could be enucleated through the same incision. Coagulation of significant bleeders was obtained with bipolar forceps. Closure of the bed of myomas was performed in 1 or 2 layers according to the depth of the uterine incision by using (Vicryl 1) sutures.

The drapes surrounding the surgical field were covered with laparotomy packs ensuring that all blood loss was measured. Blood collected in the suction apparatus was measured at the end of the operation, all irrigation fluids were premeasured and subtracted from the total contents of the suction container. Surgical sponges and laparotomy packs were weighed before surgery and immediately after use. Blood lost in surgical sponges was calculated by the 
following formula: [postoperative soaked towels weight $(\mathrm{g}$ ) minus preoperative dry towels weight ( $\mathrm{g}$ ) divided by $1.06 \mathrm{~g} / \mathrm{mL}$ (the density of blood) ${ }^{(9)}$.

Postoperative hemoglobin and hematocrit were measured 24 hours after the operation

The total volume of intraoperative blood loss was estimated by Estimation of complete blood count (CBC), hemoglobin level $(\mathrm{Hb} \%)$ and hematocrit ( $\mathrm{Ht})$ level 24hours before and after abdominal myomectomy, amount of blood in suction and number of soaked pads.

Primary outcome measure was the operative blood loss. Secondary outcome measures included the requirement for blood transfusion, the change in hemoglobin level and hematocrit level after operation, the operative time and the incidence of side effects in the three groups.

\section{Results:-}

There was no statistical significant difference between the three groups as regards the mean age, parity and size of fibroids ( $\mathrm{p}>0.05$ ). The main complaint was infertility which was found in $51.6 \%$ of group A patients, $45.2 \%$ of group B patients and $45.2 \%$ of group C patients.

There was a statistical high significant difference between preoperative and postoperative hemoglobin changes in group A, group B and group C ( $<0.001)$. But, there was a non-significant difference between the three studied groups regarding preoperative hemoglobin changes $(\mathrm{p}>0.05)$ and there was a statistically significant difference regarding postoperative hemoglobin changes $(\mathrm{p}<0.05)$.

There was a statistical high significant difference between preoperative and postoperative Hct changes in group A, group B and group C $(\mathrm{p}<0.001)$. But, there was a non-significant difference between the three studied groups regarding preoperative Hct changes $(\mathrm{p}>0.05)$ and there was a statistically significant difference regarding postoperative Hct changes $(\mathrm{p}<0.05)$.

There was a non-significant difference between the three studied groups regarding blood suction $(\mathrm{p}>0.05)$ and there was statistically a high significant difference regarding number of pads $(\mathrm{p}<0.001)$.

There was a statistical significant difference between the three groups as regards the number of patients who received blood transfusion $(\mathrm{p}<0.05)$. But, there was a statistical high significant difference between the three studied groupsas regards operative time $(\mathrm{p}<0.001)$.

Table 1:-Demographic data of the studied groups

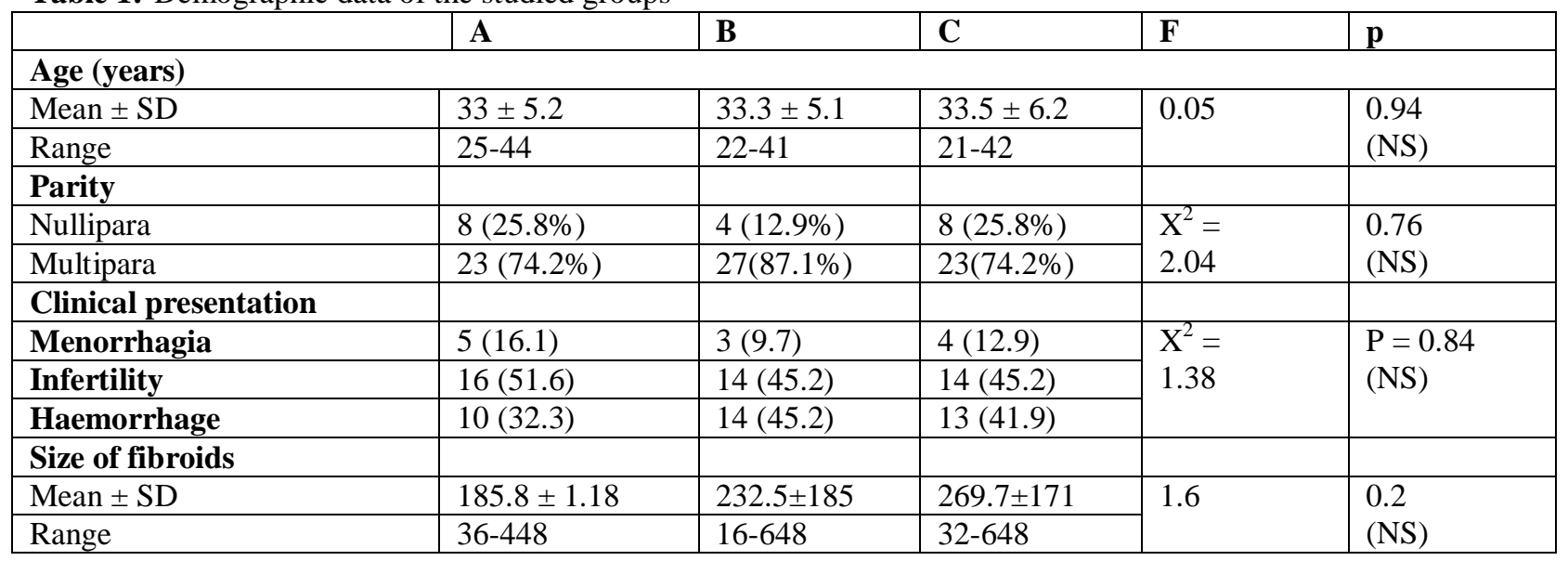

Table 2:-Hemoglobin changes among the studied groups

\begin{tabular}{|c|c|c|c|c|c|}
\hline & A & B & C & $\mathbf{F}$ & $\mathbf{p}$ \\
\hline Preoperative & & & & & \\
\hline Mean \pm SD & $11.55 \pm 0.9$ & $11.5 \pm 0.7$ & $11.3 \pm 0.65$ & \multirow[t]{2}{*}{0.33} & \multirow{2}{*}{$\begin{array}{l}0.7 \\
(\mathrm{NS})\end{array}$} \\
\hline Range & $9.9-13.8$ & $10.1-12.9$ & $110.1-12.3$ & & \\
\hline
\end{tabular}




\begin{tabular}{|l|l|l|l|l|l|}
\hline Postoperative & & & & & \\
\cline { 1 - 3 } \pm SD & $9.9 \pm 1.4$ & $10.5 \pm 0.6$ & $9.9 \pm 0.8$ & 3.9 & 0.02 \\
\cline { 1 - 2 } & $7.7-12.9$ & $9.5-12$ & $8.9-11.4$ & & $(\mathrm{~S})$ \\
\hline
\end{tabular}

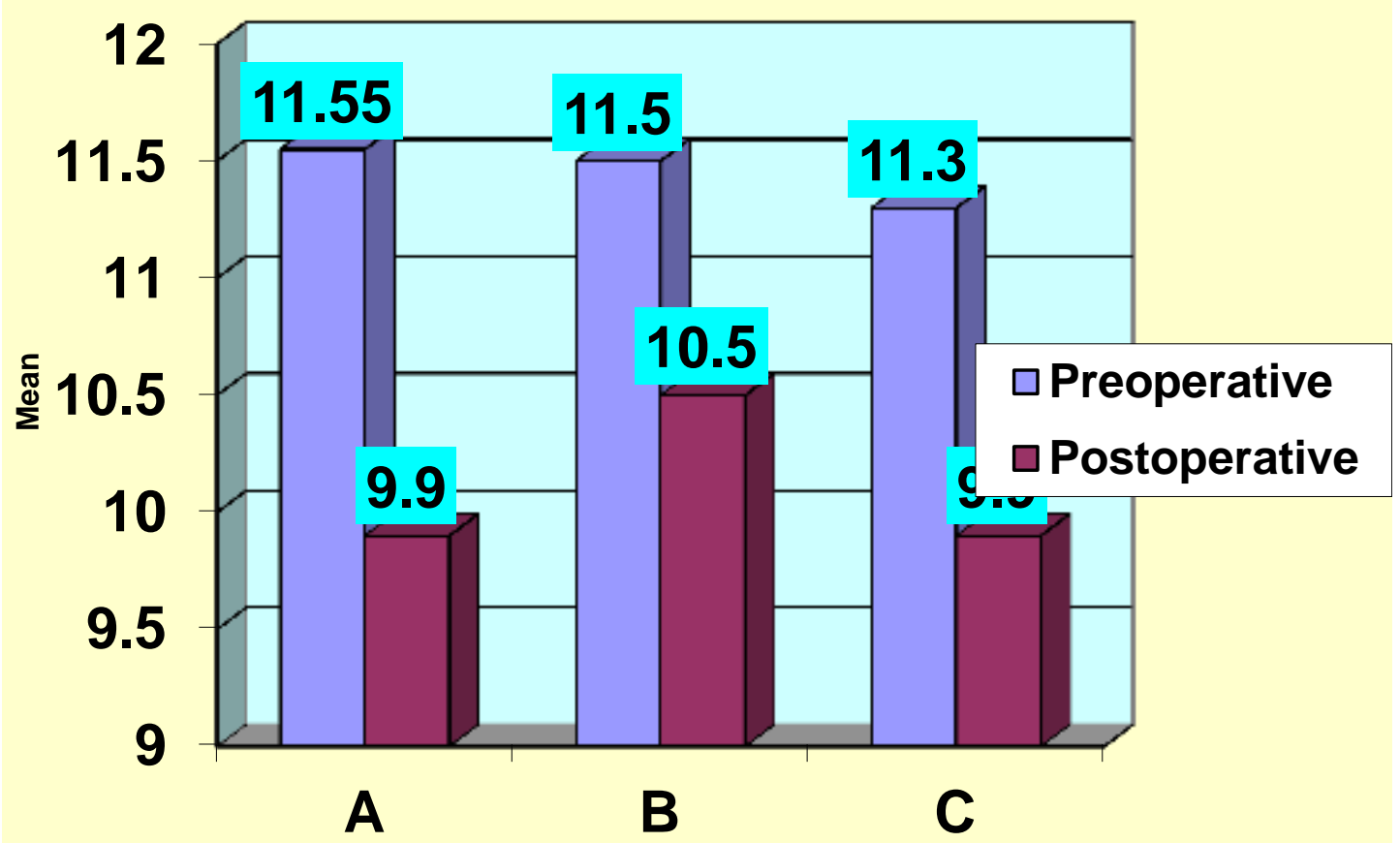

Figure 1:-Hemoglobin changes among the studied groups

Table 3:-Hct changes among the studied groups

\begin{tabular}{|c|c|c|c|c|c|}
\hline & $\mathbf{A}$ & B & $\mathrm{C}$ & $\mathbf{F}$ & $\mathbf{p}$ \\
\hline \multicolumn{6}{|c|}{ Preoperative } \\
\hline Mean \pm SD & $33.4 \pm 2.7$ & $33 \pm 3.1$ & $33.4 \pm 2.7$ & 0.19 & \multirow{2}{*}{$\begin{array}{l}0.82 \\
\text { (NS) }\end{array}$} \\
\hline Range & $28.9-41.7$ & $27.9-40.9$ & $28.7-37.3$ & & \\
\hline \multicolumn{6}{|c|}{ Postoperative } \\
\hline Mean \pm SD & $30.4 \pm 3.2$ & $31.6 \pm 3.4$ & $27.7 \pm 2.2$ & 13.2 & \multirow{2}{*}{$\begin{array}{l}0.02 \\
(\mathrm{~S})\end{array}$} \\
\hline Range & $24.9-36.6$ & $25.9-40.1$ & $24-31.2$ & & \\
\hline
\end{tabular}




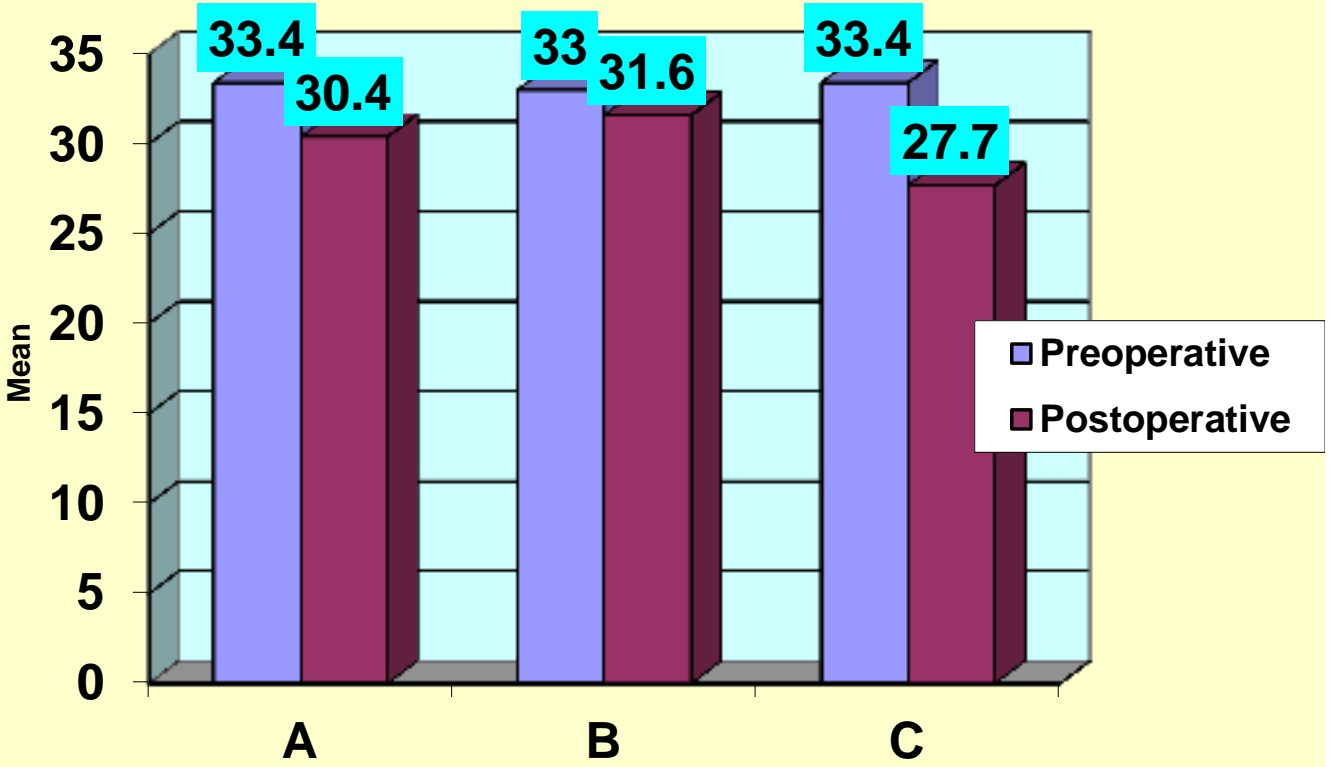

Figure 2:-Hct changes among the studied groups

Table 4:-Blood suction and number of pads among the studied groups

\begin{tabular}{|l|l|l|l|l|l|}
\hline & $\begin{array}{l}\mathbf{A} \\
(\mathbf{n = 2 1})\end{array}$ & $\begin{array}{l}\mathbf{B} \\
(\mathbf{n}=\mathbf{4})\end{array}$ & $\begin{array}{l}\mathbf{C} \\
(\mathbf{n}=\mathbf{3 1})\end{array}$ & $\mathbf{F}$ & $\mathbf{p}$ \\
\hline Blood suction & & & & & \\
\hline Mean \pm SD & $192.8 \pm 159$ & $337 \pm 188$ & $231.3 \pm 125$ & 1.79 & 0.17 \\
\hline Range & $50-500$ & $150-500$ & $50-500$ & & \\
\hline Number of pads & & & & & \\
\hline Mean \pm SD & $9.8 \pm 0.4$ & $8.5 \pm 1.1$ & $10 \pm 0$ & 38.5 & $\begin{array}{l}<0.001 \\
(\mathrm{HS})\end{array}$ \\
\hline Range & $9-10$ & $5-10$ & & & \\
\hline
\end{tabular}

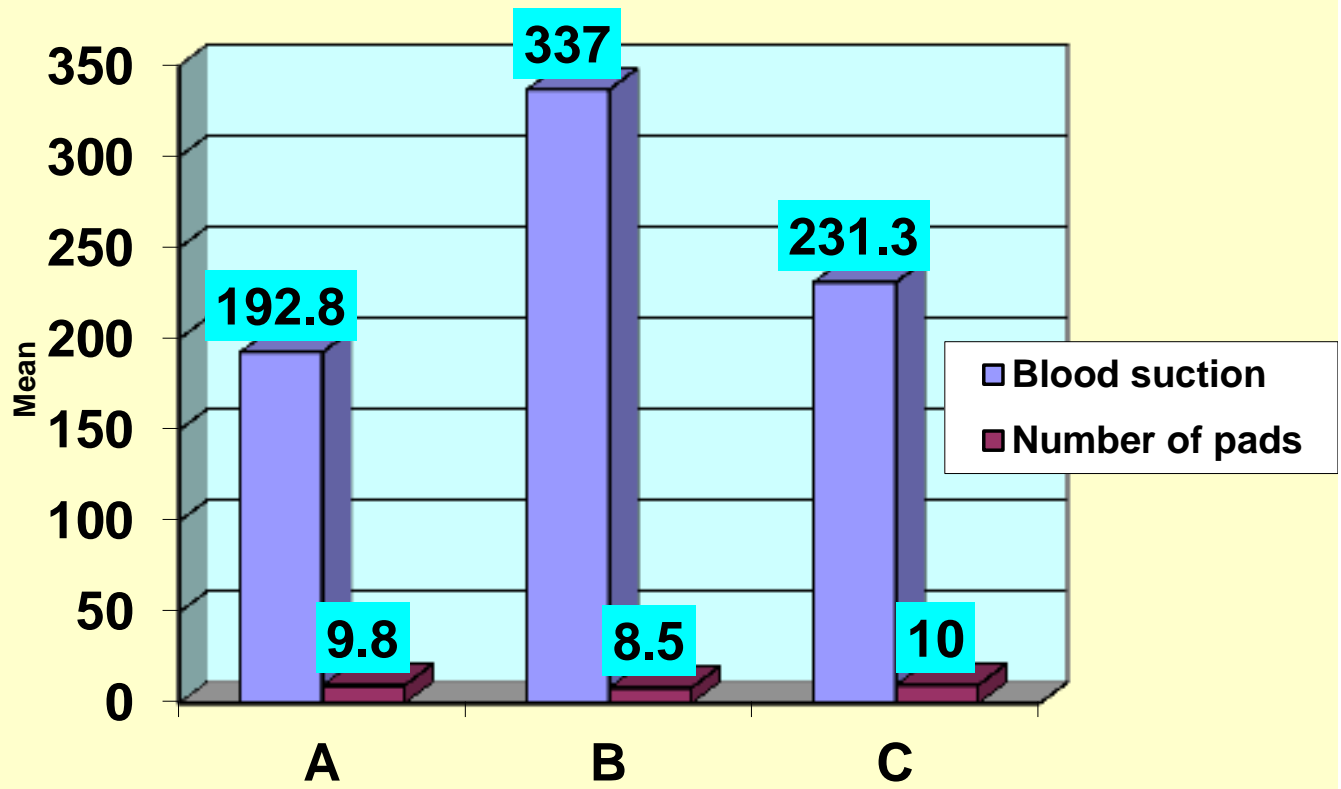

Figure 3:-Blood suction and number of pads among the studied groups 
Table 5:-Blood transfusion

\begin{tabular}{|c|c|c|c|c|c|c|c|c|}
\hline \multirow[t]{2}{*}{ Blood transfusion } & \multicolumn{2}{|l|}{$\mathbf{A}$} & \multicolumn{2}{|l|}{ B } & \multicolumn{2}{|l|}{ C } & \multirow[t]{2}{*}{$\mathbf{X}^{2}$} & \multirow[t]{2}{*}{$\mathbf{p}$} \\
\hline & No & $\%$ & No & $\%$ & No & $\%$ & & \\
\hline No & 26 & 83.9 & 29 & 93.5 & 19 & 61.3 & \multirow[t]{2}{*}{10.45} & \multirow{2}{*}{$\begin{array}{l}0.005 \\
(\mathrm{~S})\end{array}$} \\
\hline Yes & 5 & 16.1 & 2 & 6.5 & 12 & 38.7 & & \\
\hline
\end{tabular}

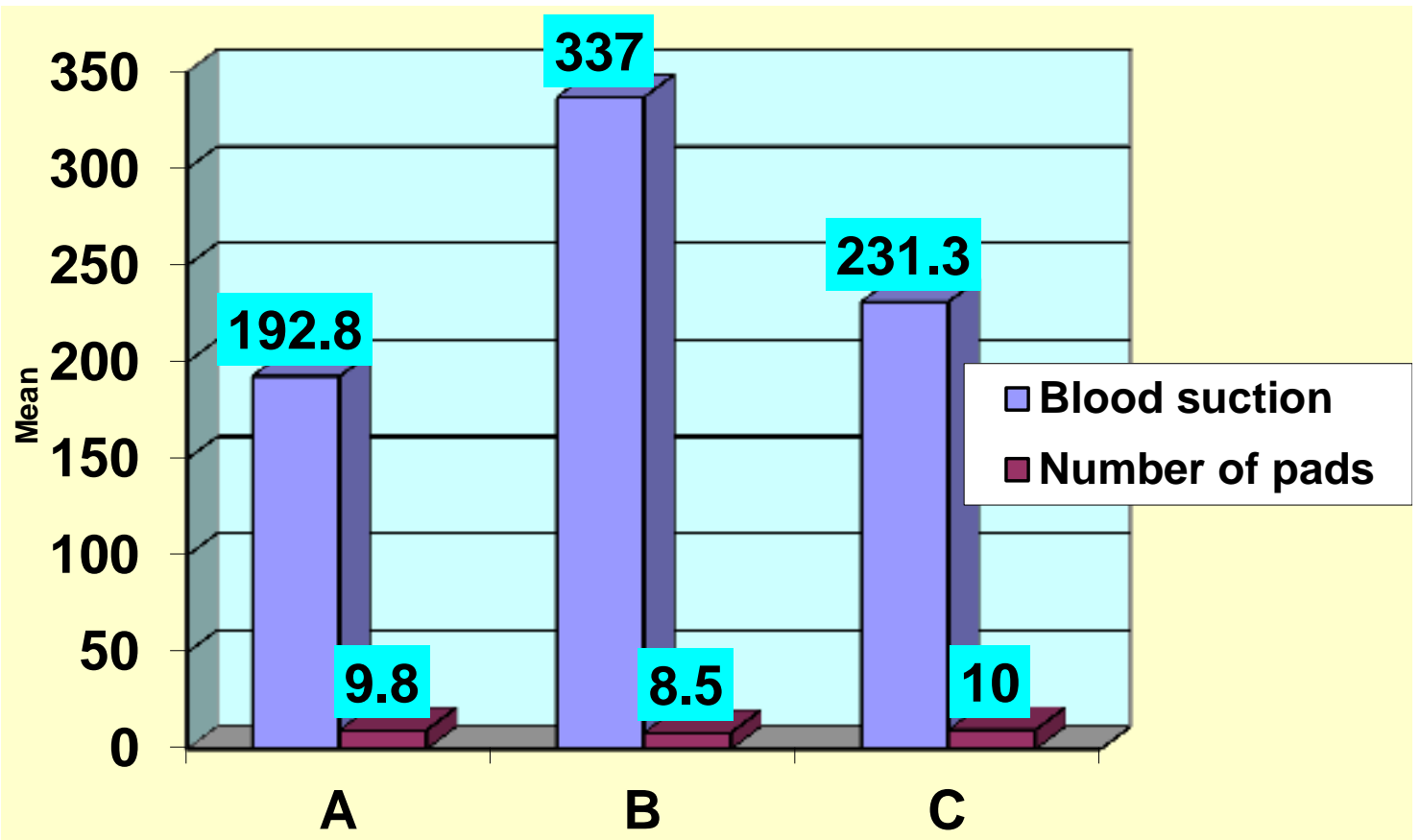

Figure 4:-Blood transfusion

\section{Discussion:-}

Excessive hemorrhage during myomectomy is a major challenge to gynecologic surgeons despite the many procedures used to reduce intraoperative blood loss, blood transfusion for women in abdominal myomectomy ${ }^{(\mathbf{1 0})}$. The effects of the interventions used to reduce blood loss during myomectomy have been inconsistent. Moreover, these interventions are varied so there is need to identify the most effective procedures with minimal adverse effects (11).

In this study, there was no statistical significant difference between the three groups as regards the mean age, parity and size of fibroids $(\mathrm{p}>0.05)$. There was statistical high significant difference between preoperative and postoperative hemoglobin changes in group A, group B and group C $(\mathrm{p}<0.001)$. There was statistical high significant difference between preoperative and postoperative Hct changes in group A, group B and group $\mathrm{C}(\mathrm{p}<$ $0.001)$. There was a non-significant difference between the three studied groups regarding blood suction $(p>0.05)$ and there was statistically a high significant difference regarding number of pads $(\mathrm{p}<0.001)$. There was a statistical significant difference between the three groups as regards the number of patients who received blood transfusion $(\mathrm{p}$ $<0.05)$. But, there was a statistical high significant difference between the three studied groupsas regards operative time $(\mathrm{p}<0.001)$.

Celik and Sapmaz ${ }^{(\mathbf{1 2})}$ investigated the effectiveness of a single preoperative dose of misoprostol in abdominal myomectomies. They suggested that administering misoprostol at $400 \mathrm{mcg}$ intravaginally 1 hour before surgery significantly decreases estimated blood loss, operating time, and need for transfusion. They concluded that a single preoperative dose of vaginal misoprostol is a simple, reliable method for reducing intraoperative blood loss and need for postoperative blood transfusion after abdominal myomectomies.

El-Shabrawy et al. ${ }^{(13)}$ determined the effectiveness of the preoperative use of a single dose of vaginal misoprostol in abdominal myomectomies and concluded that a single preoperative dose of vaginal misoprostol is a simple, 
reliable and effective method for reducing intraoperative blood loss and need for postoperative blood transfusion in abdominal myomectomies.

In the study carried out by Shokeir et al. ${ }^{(\mathbf{1 4})}$, for 108 women who underwent abdominal myomectomy, in whom 54 were given a single dose of intravaginal $20 \mathrm{mg}$ dinoprostone $\left(\mathrm{PGE}_{2}\right) 60 \mathrm{~min}$ before the operation and 54 given placebo stated that the age, body weight, number of vaginal deliveries and cesarean sections, number of previous laparotomies, and uterine size of participants in studied groups were comparable. There were no significant differences between the groups with respect to the complexity of resections. There was no significant difference regarding pre-operative $\mathrm{Hb}$ level but there was a significant difference between the two groups in postoperative $\mathrm{Hb}$ level, placepo group compared with dinoprostone group $(\mathrm{p}<0.05)$. The average blood loss was significantly higher in the placebo group $(485.7 \pm 361.3 \mathrm{~mL})$ versus dinoprostone group $(364.1 \pm 279.4 \mathrm{~mL})$. Dinoprostone led to a reduction in blood loss by $124 \mathrm{~mL}$. They found that there was a marked difference in all parameters referring to blood loss and transfusion between the two groups. Blood loss and transfusion rate were significantly greater in the group without $\mathrm{PGE}_{2}$ suppository (group $\mathrm{B}$ ) than in the group with $\mathrm{PGE}_{2}$ (group $\mathrm{A}$ ). Group $\mathrm{B}$ had a significant decrease in Hb level 24 hours after operation compared with group A ( $<<0.05)$. Theyfound that there was no significant difference in the mean operating time or the mean number of myomas excise.

Kongnyuy and Wiysonge ${ }^{(\mathbf{1 5})}$ assessed the effectiveness, safety, tolerability and costs of interventions to reduce blood loss during myomectomy .They found that misoprostol may reduce bleeding during myomectomy.

In the study carried out by Chan et al. ${ }^{(16)}, 25$ women underwent abdominal myomectomy, 13 in the study group were given a single dose $400 \mu \mathrm{g}$ of vaginal misoprostol, and 12 patients in the control group were given placebo. Misoprostol led to reduction in blood loss of $149 \mathrm{~mL}$ in the study group.

In the study carried out by Kalogiannidiset et al. ${ }^{(17)}$, 67 women with three or less myomas of a maximum diameter of $90 \mathrm{~mm}$, scheduled for minimally invasive (laparoscopic) myomectomy. The average blood loss was significantly higher in the placebo group $(217 \pm 74 \mathrm{~mL})$ versus misoprostol group $(126 \pm 41 \mathrm{~mL})$. Misoprostol led to a reduction in blood loss of $91 \mathrm{~mL}$. Blood loss was in both the study and control group of Kalogiannidis et al. than the present study, possibly due to laparoscopic approach of the procedure.

Fredericket et al. ${ }^{(\mathbf{1 8})}$ showed that the blood loss in abdominal myomectomy was significantly lower in a group of women who received pre-operative rectal misoprostol and vasopressin compared with women who received vasopressin alone. The average blood loss in the first group was $334 \mathrm{~mL}$ compared with $634 \mathrm{~mL}$ in the second group.

Other studies have assessed the effects of using misoprostol pre-operatively to reduce intra-operative bleeding during hysterectomy performed as a method of treatment for symptomatic leiomyomas. Engman et al. ${ }^{(\mathbf{1 9 )}}$ compared 49 women who received $400 \mu \mathrm{g}$ of rectal misoprostol $1 \mathrm{~h}$ before having laparoscopic-assisted vaginal hysterectomy (LAVH) for leiomyoma with 68 women who did not. They found no significant difference in blood loss between the two groups. A similar conclusion was obtained by Chaiet et al. ${ }^{(20)}$ who tested the effect of using sublingual $400 \mu \mathrm{g}$ misoprostol taken $30 \mathrm{~min}$ pre-operatively in 32 women undergoing total abdominal hysterectomy (TAH) versus 32 women receiving placebo with no observed difference in intra-operative blood loss. However, Biswas et al. ${ }^{(21)}$ showed that single dose of sublingual $400 \mu \mathrm{g}$ misoprostol $30 \mathrm{~min}$ before (TAH) resulted in a significant reduction of intra-operative blood loss.

We can conclude that the use of vaginal misoprostol or dinoprostone is an effective method to reduce intraoperative hemorrhage during abdominal myomectomy. Also, a single, preoperative dose of dinoprostone administered intravaginally could be safe and reliable method to help decrease blood loss during abdominal myomectomy.

Further prospective studies with different protocols (varying the duration of administration, quantity, route, etc...) are necessary to confirm our findings. Dinoprostone has the advantages of being uniformly prepared, accurate in dosage, stable, easy to apply and associated with minimal side effects. Careful patient selection is an essential point to avoid complications and obtain good results. 


\section{References:-}

1. Buttram, V.C. and Reiter, R.C. (2008):Uterine leiomyomas: Etiology, symptomatology, and management. Fertil Steril; 36: 433-45.

2. Aronson JK (2009): Meyler's Side Effects of Endocrine and Metabolic Drugs; Prostaglandins; 101-135.

3. Blanchard K, Clark S, Winikoff B, et al. (2002): Misoprostol for women's health: a review. Obstetrics and Gynecology; 99(2): 316-332.

4. Blanchard K, Shelley C, Beverly W, et al. (2002): Misoprostol for Women's health vol. 99, no. 2, American College of Obstetricians and Gynecologists; 316-22.

5. Carbonell Esteve JL, Acosta R, Heredia B, et al. (2008): Mifepristone for the treatment of uterine leiomyomas: a randomized controlled trial. Obstet Gynecol; 112: 1029-36.

6. Goldberg AB, Greenberg MB, Darney PD (2001): Misoprostol and pregnancy. New England Journal of Medicine; 344(1): 38-47.

7. Kongnyuy EJ and Wiysonge CS (2011): Interventions to reduce haemorrhage during myomectomy for fibroids. Cochrane Database of Systematic Reviews; 11: CD005355.

8. Kongnyuy EJ, Wiysonge CS (2007): Interventions to reduce hemorrhage during myomectomy for fibroids. Cochrane Database of systemic Reviews; Issue I. Art. No.: CD005355.

9. Ginsburg ES, Benson CB, Garfield JM, et al. (1993): The effect of operative technique and uterine size on blood loss during myomectomy: a prospective randomized study]. Fertil Steril; 60: 956-62.

10. Kongnyuy EJ \& Wiysonge CS (2008): Interventions to reduce haemorrhage during myomectomy for fibroids. Cochrane Database Syst Rev; 1: CD005355.

11. Friedman AJ, Harrison-Atlas D, Barbieri RL (2009):A randomized, placebo-controlled, double-blind study evaluating the efficacy of leuprolide acetate depot in the treatment of uterine leiomyomata. Fertil Steril; 51(2): 251-6.

12. Celik H, Sapmaz E (2003): Use of a single preoperative dose of misoprostol is efficacious for patients who undergo abdominal myomectomy. Fertil Steril; 79(5): 1207-10

13. El-Shabrawy A, Abo Elwan Y and Kotb M (2003): Use of misoprostol in abdominal myomectomy. Ain Shams Medical Journal; 54(10): 1489-1497.

14. Shokeir T, Shalaby H, Nabil H, et al. (2013): Reducing blood loss at abdominal myomectomy with preoperative use of dinoprostone intravaginal suppository: A randomized placebo-controlled pilot study. European Journal of Obstetrics and Gynecology and Reproductive Biology; 166: 61-63.

15. Kongnyuy EJ and Wiysonge CS (2014): Interventions to reduce haemorrhage during myomectomy for fibroids. Cochrane Database Syst Rev; 8: CD005355.

16. Chan LY (2004): Use of a single preoperative dose of misoprostol is efficacious for patients who undergo abdominal myomectomy. Fertil Steril; 81: 1060-1061.

17. Kalogiannidis I, Xiromeritis P, Prapas N, Prapas Y(2011): Intravaginal misoprostol reduces intraoperative blood loss in minimally invasive myomectomy: a randomized clinical trial. Clin Exp Obstet Gynecol; 38: 4649.

18. Frederick S, Frederick J, Fletcher $\mathbf{H}$ et al (2013). A trial comparing the use of rectal misoprostol plus perivascular vasopressin with perivascular vasopressin alone to decrease myometrial bleeding at the time of abdominal myomectomy. FertilSteril; 100: 1044-1049

19. Engman M, Granberg S, Williams AR, et al. (2009): Mifepristone for treatment of uterine leiomyoma. A prospective randomized placebo controlled trial. Hum Reprod; 24: 1870-9.

20. Chai J, Hon E, Li CF et al (2011). A pilot study of pre-operative misoprostol in reducing operative blood loss during hysterectomy.Eur J ObstetGynecolReprodBiol; 158: 72-75.

21. Biswas J, Chaudhuri P, Mandal A et al (2013). Effect of a single preoperative dose of sublingual misoprostol on intraoperative blood loss during total abdominal hysterectomy. Int J Gynecol Obstet; 122: 244247. 